\title{
Clinical Study on Deviated Nasal Septum and Its Associated Pathology
}

\author{
Prayaga N. Srinivas Moorthy' ${ }^{1}$, Srikanth Kolloju1, Srivalli Madhira², Ali Behman Jowkar1 \\ ${ }^{1}$ Department of E.N.T.-Head \& Neck Surgery, Deccan College of Medical Sciences, Hyderabad, India \\ ${ }^{2}$ Sai's Institute of Endocrinology and Speciality Clinics, Hyderabad, India \\ Email: pns moorthy@yahoo.com
}

Received 16 December 2013; revised 5 January 2014; accepted 13 January 2014

Copyright $(02014$ by authors and Scientific Research Publishing Inc.

This work is licensed under the Creative Commons Attribution International License (CC BY).

http://creativecommons.org/licenses/by/4.0/

(c) (i) Open Access

\begin{abstract}
Deviated nasal septum is a frequently occurring condition that can cause nasal obstruction in an individual. It may result in permanent changes in the nasal and sinus mucosa because of altered ventilation of the nasal cavity. The present study makes an attempt to review its incidence and its associated pathology. Our study involves two groups of patients with 100 patients in each group. The first group consists of patients who are having nasal obstruction as a chief complaint and have deviated nasal septum. The second group consists of patients with either ear or throat complaints without any nasal symptoms, but were noted to have deviation of nasal septum on examination. An analysis was made to determine whether any particular type of deviation is more prone to develop pathology than other types. Our study shows that an " $\mathrm{S}$ " shaped deviation is more prone to be associated with ear, nose and throat pathology.
\end{abstract}

\section{Keywords}

Deviated Nasal Septum; Symptoms; Septoplasty

\section{Introduction}

The nasal septum comprising of bony and cartilaginous parts separates the nasal cavity into right and left sides both anatomically and physiologically. It is an accepted fact that some amount of deviation of nasal septum is common and having a perfectly straight septum is a rarity [1]. Various reasons have been attributed to occurrence of deviated nasal septum (DNS) including racial factors, birth molding of septum during parturition, trauma and developmental deformities of septum [2]. Deviated nasal septum (DNS) can be asymptomatic in an individual or may cause nasal obstruction and symptoms of rhino sinusitis like nasal discharge, facial pain, epistaxis, disturbance of smell. The pathology in sinonasal cavity can also affect the functioning of throat and ear and surgery of septum and sinuses is indicated in such a situation. In our present study we tried to analyze the 
prevalence of various types of deviated nasal septum and their associated ear, nose and throat pathology.

\section{Material and Methods}

The present prospective study is conducted at a tertiary care referral hospital over a period of two years. In our study we have included two groups of patients of 100 each of which the first group (Group I) consists of patients complaining of nasal obstruction. The second group (Group II) consists of patients with either ear or throat complaints without any nasal symptoms, but were noted to have deviation of nasal septum on examination. Hence we have two groups of patients who have deviated nasal septum with one group (Group I) having predominant nasal complaints and the other group (Group II) with no nasal complaints but with ear and throat pathologies like chronic tonsillitis, chronic pharyngitis, chronic suppurative otitis media etc. Children less than 5 years of age are excluded from the study as they will not be able to express their symptoms. A thorough clinical examination and diagnostic nasal endoscopy is done to evaluate the nasal cavity and nasal septum in all the patients. Based on various classification systems proposed earlier we have classified the observed DNS clinically into various types like anterior deviation, posterior deviation, caudal dislocation, "C" shaped, "S" shaped deviation (either in cephalo-caudal or antero-posterior direction), spur impinging on lateral nasal wall, thickened septum [3]-[8]. All the patients in Group I were subjected Computerized Tomography scan of paranasal sinuses (CT PNS). The patients in Group II were advised X-Ray of Paranasal sinuses initially and they were subjected to CT PNS if the X-ray PNS showed any sinus pathology. The aim of the study is to determine whether any particular type of septal deviation is more prone to be associated with the ear, nose and throat pathology than other types, irrespective of it being symptomatic or not.

\section{Results}

The group of patients who complained of nasal obstruction (Group I) are analyzed first. Maximum number of patients i.e. $45 \%$ of the patients in our study is in the age group of $16-25$ years (Table 1). The next common age group in this study is 26 - 35 i.e., 29\%. In the $6-15$ years age group it is $11 \%$. It is also noticed as $11 \%$ in the age group of 36 - 45 years. The lowest incidence is seen in 46 - 55 years age group. It is similar to the study of Rodney P Lusk where the incidence of septal deviation in pediatric age group is $10.4 \%$ [9]. The incidence of DNS is more in males than females (Table 2) with an approximate ratio of 2:1 which is in agreement to a study done by Dipak Ranjan Nayak [10]. The deviation was more common on left side (Table 3). All patients (100\%) complained of nasal obstruction in Group I (Table 4 and Chart 1). The second most common symptom was nasal discharge. Head ache was seen $20 \%$ of patients which may be because of sinusitis or mucosal contact points. The incidence of excessive sneezing in this study is $15 \%$ and these patients were also having allergic rhinitis. The study made by Haytham Kubba, Brian J.G. showed an incidence of $12 \%$ sneezing [11]. Thickened septum is seen in $3 \%$ of cases.

\begin{tabular}{|ccc|}
\hline Table 1. Age incidence in patients of Group I and II. \\
\hline Age group (Years) & Group I & Group II \\
\hline $6-15$ & 11 & 20 \\
$16-25$ & 45 & 37 \\
$26-35$ & 29 & 30 \\
$36-45$ & 11 & 6 \\
$46-55$ & 4 & 5 \\
\hline
\end{tabular}

Table 2. Sex Incidence showing males commoner than females.

\begin{tabular}{ccc} 
Gender & Group I & Group II \\
\hline Male & 64 & 55 \\
Female & 36 & 45 \\
\hline
\end{tabular}


Table 3. Deviation towards the left side is more common than the right.

\begin{tabular}{ccc}
\hline Side of deviation & Group I & Group II \\
\hline Right & 35 & 38 \\
Left & 55 & 53 \\
Equal (S Shaped) & 10 & 9 \\
\hline
\end{tabular}

Table 4. Symptoms complained by patients of Group I.

\begin{tabular}{cc}
\hline Symptoms & No. of Patients \\
\hline Persistent Nasal obstruction & 74 \\
Alternating nasal obstruction & 26 \\
Nasal discharge & 41 \\
Head ache & 20 \\
Sneezing & 15 \\
Throat discomfort & 8 \\
Post nasal drip & 35 \\
Epistaxis & 3 \\
Snoring & 30 \\
Hyposmia/Anosmia & 18 \\
\hline
\end{tabular}

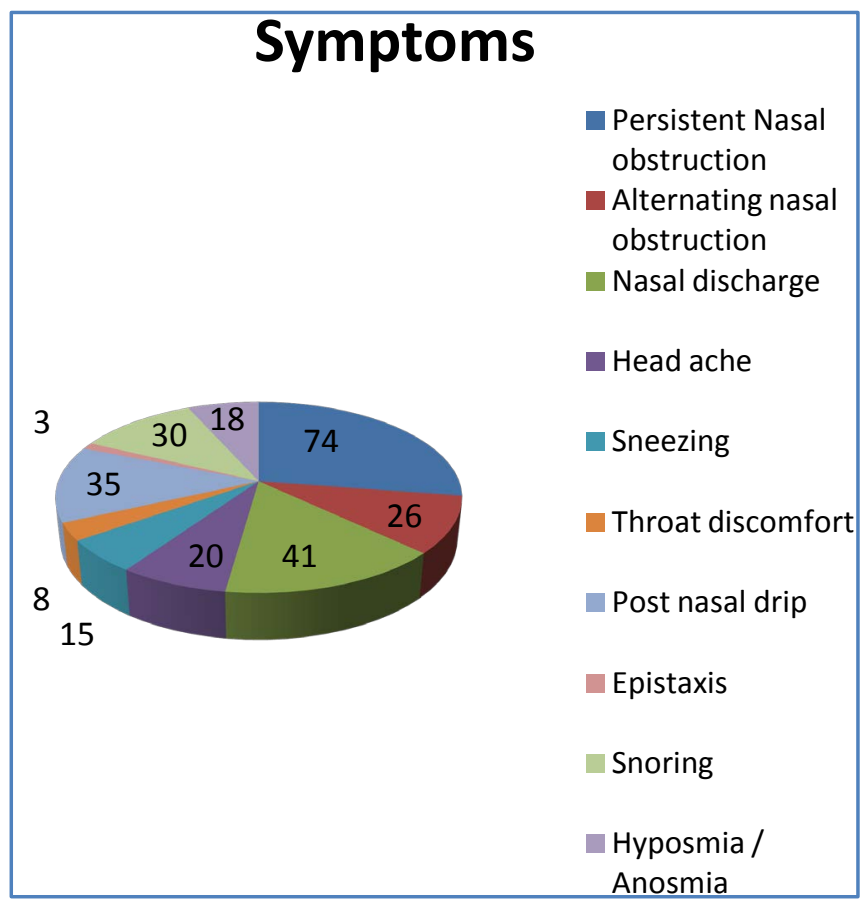

Chart 1. Symptoms complained by patients of Group I.

The patients in Group II were not having any nasal symptoms but were having chronic tonsillitis, chronic pharyngitis, and tubotympanic type of chronic suppurative otitis media (CSOM). They were found to have deviated nasal septum on clinical examination. Our study has more number of males even in Group II and patients 
between 16 - 25 years were more common. The absence of nasal symptoms, even in presence of significant sinonasal pathology in at least 35 patients of Group II, could not be explained by our study but it is possible that the patients have ignored subtle nasal symptoms in presence of more distressing ear and throat complaints of their disease.

On clinical examination the septum having anterior deviation in Group I is $11 \%$ and is $14 \%$ in the Group II. The incidence of posterior deviation is $4 \%$ in both symptomatic and Group II. The incidence of caudal deviation is $16 \%$ in Group I and $10 \%$ in Group II. The incidence of $C$ shaped deviation is $40 \%$ in the Group I and $50 \%$ in the Group II. The "S" shaped deviation in this study is 30\% in Group I and 19\% in the Group II (Table 5 and Chart 2). The spur impinging on lateral nasal wall is $20 \%$ in Group I of this study and $3 \%$ in the Group II. The septal deformity resulting in touching the middle turbinate causing narrowing of the middle meatus is seen in $20 \%$ of cases in this study. In terms of identifying the type of DNS, clinical examination appears to be adequate as there was no additional information obtained on CT scan towards identification of type of DNS. CT scan of paranasal sinus gave a clear picture of lateral wall anatomy and sinus pathology.

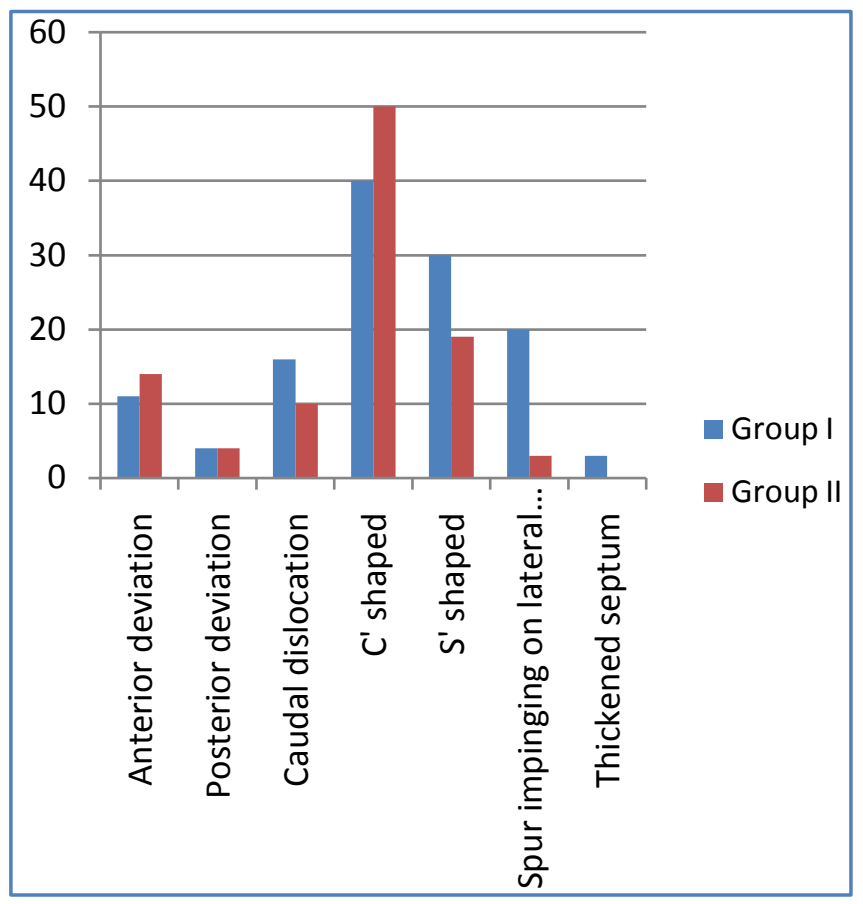

Chart 2. Various types of deviated nasal septum found in both the groups.

Table 5. Various types of deviated nasal septum found in both the groups. indicates that the total in Group I is more than 100 as the septal spur is in combination with "C" or "S" shaped deviation.

\begin{tabular}{ccc}
\hline Type of DNS & Group I* & Group II \\
\hline Anterior deviation & 11 & 14 \\
Posterior deviation & 4 & 4 \\
Caudal dislocation & 16 & 10 \\
“C” shaped & 40 & 50 \\
"S” shaped & 30 & 19 \\
Spur impinging on lateral wall & 20 & 3 \\
Thickened septum & 3 & 0 \\
\hline
\end{tabular}


In Group I patients the associated anatomical variants on lateral nasal wall as diagnosed by CT Scan were Concha bullosa (CB), and Paradoxical middle turbinate (PMT) which were observed in $23 \%$ and $15 \%$ of patients respectively (Table 6). Clinical examination showed polypi on anterior rhinoscopy examination in 32\% of cases, where as CT Scan showed involvement of sinuses with homogenous opacity due to mucosal disease in $65 \%$ of cases of Group I. These cases showed unilateral or bilateral involvement of single or multiple sinuses. The inferior turbinate was hypertrophied in $40 \%$ of cases of Group I. Atrophic rhinitis changes were seen in $4 \%$ of cases, especially in patients having gross " $\mathrm{C}$ " shaped deviations.

In Group II patients there were no nasal polypi seen but significant sinus involvement as noted in CT scan was observed in 35 patients of whom 15 were having " $S$ " shaped DNS in antero-posterior direction. 8 patients were having "C" shaped DNS, 4 patients each of anterior and posterior deviation of septum, 3 were having caudal dislocation and 1 patient was with spur (Table 7). Interestingly none of these 35 patients were complaining any nasal symptoms of which 20 patients were having tubotympanic type of CSOM (Figure 1) and 10 were having chronic pharyngitis.

All the patients of Group I were offered both medical and surgical treatment like Septoplasty, polypectomy and Functional endoscopic sinus surgery (FESS) tailored according to the clinical and CT scan findings [12] [13]. 20 patients in Group II underwent Septoplasty with FESS prior to their ear surgery for CSOM.

Out of total 200 patients comprising both the groups 113 patients were having significant sinonasal disease as evidenced by CT scan. Among these 49 patients were having "S" shaped DNS in an anteroposterior direction and all except 8 patients of these were having sinonasal disease. Based on the available statistical data from our study for occurrence of sinonasal pathology with "S" shaped DNS the calculated p-value by chi-square test with $2 \times 2$ contingency table is less than 0.001 which is highly significant. The association between sinus disease and

Table 6. Sinonasal pathology noted in Group I patients. *OMC—osteomeatal complex, PMT—Paradoxical middle turbinate and $\mathrm{CB}$-Concha bullosa.

\begin{tabular}{|c|c|c|c|c|c|}
\hline \multirow{2}{*}{ Type } & \multirow{2}{*}{ No. of Patients } & \multirow{2}{*}{$\begin{array}{c}\text { Polyp/OMC } \\
\text { block }^{*}\end{array}$} & \multirow{2}{*}{ Pansinusitis } & \multicolumn{2}{|c|}{ Anatomical Variation } \\
\hline & & & & PMT & CB \\
\hline Anterior Deviation & 11 & - & 2 & 2 & 4 \\
\hline Posterior Deviation & 4 & 4 & 3 & 2 & 1 \\
\hline Caudal Dislocation & 16 & - & 8 & 3 & 2 \\
\hline “C” Shaped & 40 & 15 & 20 & 5 & 4 \\
\hline "S" Shaped & 30 & 7 & 25 & 1 & 8 \\
\hline Spur & 20 & 6 & 6 & 2 & 4 \\
\hline Thickened Septum & 3 & - & - & - & - \\
\hline
\end{tabular}

Table 7. Sinonasal pathology noted in Group II patients. ${ }^{*}$ OMC—osteomeatal complex, PMT_Paradoxical middle turbinate and CB-Concha bullosa.

\begin{tabular}{ccccccc}
\hline Type & No. of Patient & Polyp & OMC block & Pansinusitis & \multicolumn{2}{c}{ Anatomical Variation } \\
\cline { 4 - 7 } & & - & 2 & 2 & PMT & CB \\
\hline Anterior Deviation & 14 & - & 1 & 3 & 0 & 1 \\
Posterior Deviation & 4 & - & 3 & 0 & 1 & 1 \\
Caudal Dislocation & 10 & - & 4 & 4 & 0 & 0 \\
“C” Shaped & 50 & - & 6 & 1 & 1 & 5 \\
"S" Shaped & 19 & - & & - & - & - \\
Spur & 3 & - & & & - \\
Thickened Septum & 0 & &
\end{tabular}




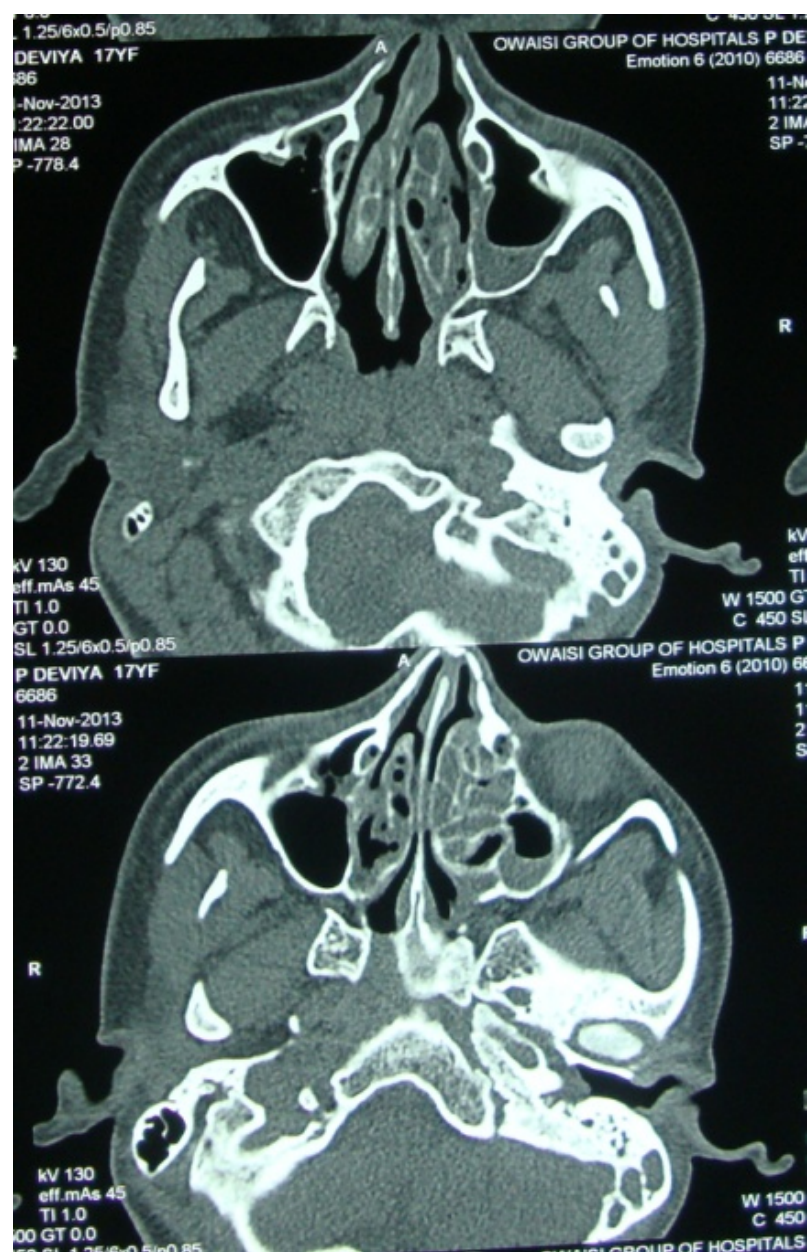

Figure 1. A patient of left CSOM (Group II) showing disease in left middle ear and mastoid having a "C" shaped DNS towards right, left Concha bullosa and sinusitis involving left maxillary and ethmoid sinuses without any nasal symptoms.

presence of other types of DNS (other than "S" shaped) is not statistically significant in our study.

\section{Conclusion}

Deviated nasal septum can be associated with significant sinonasal disease even in absence of any nasal symptoms, especially an "S" shaped DNS which showed statistically significant correlation with sinus disease in our study. Larger multi-centre studies are required to confirm our study findings before we can propose that a preventive Septoplasty can be contemplated for an "S" shaped septum without nasal symptoms to curtail development of possible ear, nose and throat pathology.

\section{References}

[1] Gray, L.P. (1978) Deviated Nasal Septum. Incidence and Etiology. Annals of Otology, Rhinology, and Laryngology, 87, 3-20.

[2] Neskey, D., Eloy, J.A. and Casiano, R.R. (2009) Nasal, Septal and Turbinate Anatomy and Embryology. Otolaryngologic Clinics of North America, 42, 193-205. http://dx.doi.org/10.1016/j.otc.2009.01.008

[3] Mladina, R., Čujić, E., Šubarić, M., et al. (2008) Nasal Septal Deformities in Ear, Nose, and Throat Patients: An International Study. American Journal of Otolaryngology, 29, 75-82. http://dx.doi.org/10.1016/j.amjoto.2007.02.002

[4] Mladina, R., Heinzel, B., Belussi, L. and Passali, D. (1995) Staging in Rhino Sinusitis Septal Deformities. Rivista Ita- 
liana Di Oto Laringologi, 7, 16.

[5] Guyuron, B., Uzzo, C.D. and Scull, H. (1999) A Practical Classification of Septonasal Deviation and an Effective Guide to Septal Surgery. Plastic and Reconstructive Surgery, 104, 2202-2212. http://dx.doi.org/10.1097/00006534-199912000-00039

[6] Baumann, I. and Baumann, H. (2007) A New Classification of Septal Deviations. Rhinology, 45, $220-223$.

[7] Rao, J.J., Kumar, E.C.V., et al. (2005) Classification of Nasal Septal Deviations-Relation to Sinonasal Pathology. Indian Journal of Otolaryngology and Head and Neck Surgery, 57, 199-201.

[8] Rehman, A., Hamid, S., Ahmad, M. and Rashid, A. (2012) A Prospective Study of Nasal Septal Deformities in Kashmiri Population Attending a Tertiary Care Hospital. International Journal of Otolaryngology and Head \& Neck Surgery, 1, 77-84. http://dx.doi.org/10.4236/ijohns.2012.13016

[9] Lusk, R.P., McAlister, B. and Fouley, A. (1996) Anatomic Variation in Pediatric Chronic Sinusitis. A CT Study. Otolaryngologic Clinics of North America, 29, 75-91.

[10] Nayak, D.R., Balakrishnan, R. and Deepak Murty, K. (2002) Produl Hazarika. Indian Journal of Otolaryngology and Head and Neck Surgery, 54, 20-24.

[11] Haytham Kubba and Brian J. G. Bingham (2001) Endoscopy in the Assessment of Children with Nasal Obstruction. The Journal of Laryngology \& Otology, 115, 380-384. http://dx.doi.org/10.1258/0022215011907929

[12] Cottle, J.M. (1958) The Maxilla-Premaxillary Approach to Extensive Nasal Septum Surgery. Archives of Otolaryngology—Head and Neck Surgery, 68, 301-306. http://dx.doi.org/10.1001/archotol.1958.00730020311003

[13] Stammberger, H. (1991) Functional Endoscopic Sinus Surgery, the Messerklinger Techique. B. C. Decker (Inc), Philadelphia, 156-168. 